\title{
Micro-mesoporous carbons from rice husk as active materials for supercapacitors
}

\author{
Marina V. Lebedeva ${ }^{1}$ Petr M. Yeletsky ${ }^{1} \cdot$ Artem B. Ayupov $^{1} \cdot$ Aleksey N. Kuznetsov $^{1,2}$ • \\ Vadim A. Yakovlev ${ }^{1} \cdot$ Valentin N. Parmon ${ }^{1,2}$
}

Received: 16 March 2015/Accepted: 16 September 2015/Published online: 6 October 2015

(c) The Author(s) 2015. This article is published with open access at Springerlink.com

\begin{abstract}
Activated carbons were prepared from rice husk carbonized in the fluidized catalysts bed reactor. Using the different activating agents, samples with BET surface area in the range from 540 to $3060 \mathrm{~m}^{2} / \mathrm{g}$ were achieved. Using sodium or potassium carbonates results in the BET surface area up to $1400 \mathrm{~m}^{2} / \mathrm{g}$. Hydroxides of sodium or potassium yield the samples with the higher BET surface area (up to $3060 \mathrm{~m}^{2} / \mathrm{g}$ ). Textural peculiarities of the carbons were studied by the adsorption of nitrogen at $77 \mathrm{~K}$ and of carbon dioxide at $273 \mathrm{~K}$. As active materials for supercapacitors, the porous carbon samples were examined by cyclic voltammetry and chronopotentiometry in galvanostatic mode in $1 \mathrm{M} \mathrm{H}_{2} \mathrm{SO}_{4}$ as the electrolyte using home-made three-electrode electrochemical glass cell. Gravimetric capacitance of the carbons is linearly proportional to the BET surface area and reaches 230 and $196 \mathrm{~F} / \mathrm{g}$ at discharge current density of 0.2 and $1 \mathrm{~A} / \mathrm{g}$, respectively, for the samples with the highest surface area.
\end{abstract}

Keywords Activation - Carbon material - Carbonization · Rice husk · Supercapacitor

Marina V. Lebedeva

lebedeva@catalysis.ru

1 Boreskov Institute of Catalysis, Pr. Akademika Lavrentieva 5, Novosibirsk, Russia 630090

2 Novosibirsk State University, Pirogova St. 2, Novosibirsk, Russia 630090

\section{Introduction}

Among various devices for electric energy storage, supercapacitors take an intermediate position between batteries and conventional capacitors. They possess unique energetic characteristics, showing higher power density than batteries and higher energy density than capacitors. In addition, supercapacitors demonstrate long life cycle, good reversibility and low maintenance cost [1-3]. All these benefits draw a lot of attention to research and development of the new active materials suitable for the supercapacitor construction.

The specific character of energy storage requires tailored textural characteristics of the practical materials used in supercapacitors: extended surface area and open porous structure, accessible for ions of the electrolyte. Carbons presented in variety forms and modifications help prospectively to improve existing supercapacitors thanks to physico-chemical properties: sufficient conductivity, good corrosion resistance, temperature stability, relatively low cost and possibility to vary textural properties [4]. Micro[5-8] and mesoporous [9-12] carbon materials have been widely investigated as active electrode materials for the supercapacitors.

Now, economic reasons and environmental challenges make biomass attract significant attention as a source for production of the carbon materials. Woods, leaves, beer lees, rice husk and other biomass precursors have been reported as a raw material for such production $[5,9,13-$ 20].

Rice husk (RH) is a large-scale agricultural waste without any relevant commercial applications. High amount of amorphous silica makes rice husk conversion difficult. However, on the other hand, the presence of silica allows to consider RH as template-containing precursor for 
the preparation of porous carbons with textural characteristics depending on the template phase properties. In our previous publications [21-23], two methods of preparation of porous carbons, from RH carbonized in the fluidized catalyst bed reactor, have been described-with the use of alkalis and carbonates of $\mathrm{Na}$ and $\mathrm{K}$.

When using carbonates of $\mathrm{Na}$ or $\mathrm{K}$ in powdered state, the developed method is close to be an analog of the template synthesis technique, but in this case no additional template material is needed, since it is already contained in RH. Here, porosity in the prepared porous carbons is being developed by the following scheme (Fig. 1):

- Formation of water-soluble silicates by high-temperature treatment;

- Washing out the $\mathrm{C} /$ silicate composites.

In the case of alkalis, $\mathrm{SiO}_{2}$ phase certainly contributes to the development of porosity, but there is also a significant reconstruction of carbon phase because of its interaction with alkalis. That is why a detection of the contribution of $\mathrm{SiO}_{2}$ phase in the porosity development is complicated enough.

Thereby, in the present study, series of the carbon materials has been prepared from the rice husk carbonized in the fluidized catalyst bed reactor-by $\mathrm{Na}$ and $\mathrm{K}$ carbonates and alkalis activation. Variation of activation conditions allowed preparing materials with different textural characteristics. Carbons were investigated as active electrode materials for the supercapacitors; influence of the textural parameters on electrochemical response and capacitive characteristics was discussed.

\section{Experimental}

\section{Synthesis of carbons}

\section{Carbonization of rice husk in fluidized catalyst bed (FCB) reactor}

Rice husk was received from Krasnodar region (Russia). Asreceived RH contains about $19 \mathrm{wt} \%$ of ash which is mainly silica. Before the carbonization process, as-received RH was milled to particles of about $1 \mathrm{~mm}$ size. RH carbonization was carried out in a tubular stainless steel reactor of $75 \mathrm{~mm}$ i.d., with $1000 \mathrm{~mm}$ height of catalyst bed of 3.51 in volume. The reactor scheme is presented in Fig. 2.

The feedstock was fed to the reactor within air stream (molar ratio of $\mathrm{O}_{2}$ in air to carbon in $\mathrm{RH}$ was equal 2). The contact time of $\mathrm{RH}$ with the catalyst was estimated as $0.3-0.4 \mathrm{~s}$. The temperature of the process was 465,550 , and $600{ }^{\circ} \mathrm{C}$ and controlled by external electroheaters; in the case of $600{ }^{\circ} \mathrm{C}$, the process carried out in autothermal mode. A commercial $\mathrm{CuCr}_{2} \mathrm{O}_{4}+\mathrm{MgO} / \gamma-\mathrm{Al}_{2} \mathrm{O}_{3}$ catalyst (IC-12-73, Katalizator Co.) with $15 \mathrm{wt} \%$ of the active component was employed. Temperatures $465-600{ }^{\circ} \mathrm{C}$ have been found to be optimal for $\mathrm{RH}$ carbonization in the reactor in previous studies [21]. Increasing the carbonization temperature leads to increase of ash content in the obtained composites (Table 1) and to an increase of size of $\mathrm{SiO}_{2}$ phase particles [24] that can affect to texture characteristics of obtaining porous carbons.

The obtaining carbonized RH is carbon-silica nanocomposite $\left(\mathrm{C} / \mathrm{SiO}_{2}\right)$ materials with homogenously distributed carbon and silica phases. More detailed studies of carbonized RH and influence of the carbonization conditions in $\mathrm{FCB}$ reactor on the $\mathrm{C} / \mathrm{SiO}_{2}$ properties are reported in [21]. Some characteristics of $\mathrm{C} / \mathrm{SiO}_{2}$ composites utilized for further carbon materials preparation are shown in Table 1.

\section{Carbonate and alkali activation of carbonized $R H$}

Porous carbons were obtained from the carbonized RH (C/ $\mathrm{SiO}_{2}$ composites) by two activating methods-with employing of carbonates and hydroxides of $\mathrm{K}$ and $\mathrm{Na}$. For preparation of the carbons, a static stainless steel reactor of 8.51 of volume and of productivity by the carbons 50-200 g per 1 run has been used.

In the case of carbonates' utilization, $\mathrm{C} / \mathrm{SiO}_{2}$ composites were thoroughly mixed with powdered $\mathrm{K}_{2} \mathrm{CO}_{3}+\mathrm{Na}_{2} \mathrm{CO}_{3}$ equimolar mixture (to reduce $T_{\text {melt }}$ of the carbonate agent) or individual $\mathrm{K}_{2} \mathrm{CO}_{3}$ up to getting a homogenous mechanical mixture. Molar ratio of the carbonates to $\mathrm{SiO}_{2}$ of carbonized RH was varied from 1:1 to 3:1. The mixture was heated up to 900,950 and $1000^{\circ} \mathrm{C}$ with holding activation temperature for $0.5-3 \mathrm{~h}$; the heating rate was $3{ }^{\circ} \mathrm{C} \min ^{-1}$.
Fig. 1 Scheme of the use of $\mathrm{SiO}_{2}$ phase of the carbonized $\mathrm{RH}$ as template phase for obtaining of porous carbons
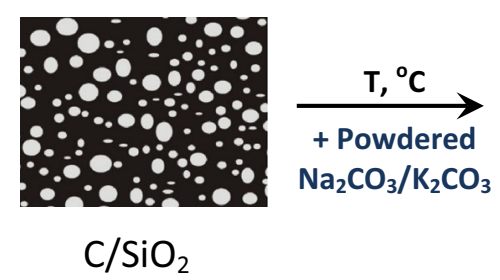

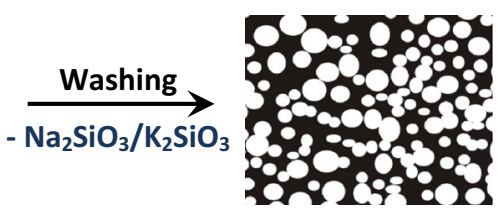

Porous carbons

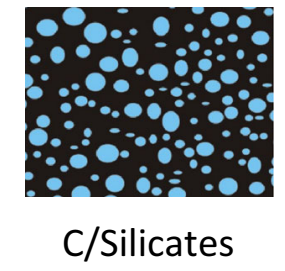


In the case of alkali activation, $\mathrm{C} / \mathrm{SiO}_{2}$ composites were mixed with scaly either $\mathrm{KOH}$ or $\mathrm{NaOH}$ (without additional water). Ratios of $\mathrm{KOH}$ and $\mathrm{NaOH}$ to $\mathrm{C} / \mathrm{SiO}_{2}$ precursor were $4: 1$ and $3: 1$ by weight, respectively. The mixture of precursor and alkalis was dried at $320^{\circ} \mathrm{C}$ for $4 \mathrm{~h}$ to remove traces of water from alkalis and $\mathrm{C} / \mathrm{SiO}_{2}$ pores. After the drying, in the case of $\mathrm{KOH}$, the mixture was heated up to $750{ }^{\circ} \mathrm{C}$ with following switching off the heater without holding at activating temperature; in the case of $\mathrm{NaOH}$, the mixture was heated up to $800{ }^{\circ} \mathrm{C}$ with holding for $1 \mathrm{~h}$. Heating rate was also $3{ }^{\circ} \mathrm{C} \mathrm{min}^{-1}$. There were two approaches of $\mathrm{KOH}$ activation; the second differed from the first one by using a mechanical stainless still agitator built-in into the reactor through the reactor head to intensify the activation process.

After the both type of the activation, the obtained products were washed from water-soluble silicates and other $\mathrm{Na}$ and $\mathrm{K}$ compounds step by step: (1) by deionized water until the $\mathrm{pH}$ was neutral; (2) by $3 \mathrm{M} \mathrm{HCl}$ solution (3) by deionized water until the $\mathrm{pH}$ was neutral. The washed materials were dried overnight at $120^{\circ} \mathrm{C}$. In Table 2,

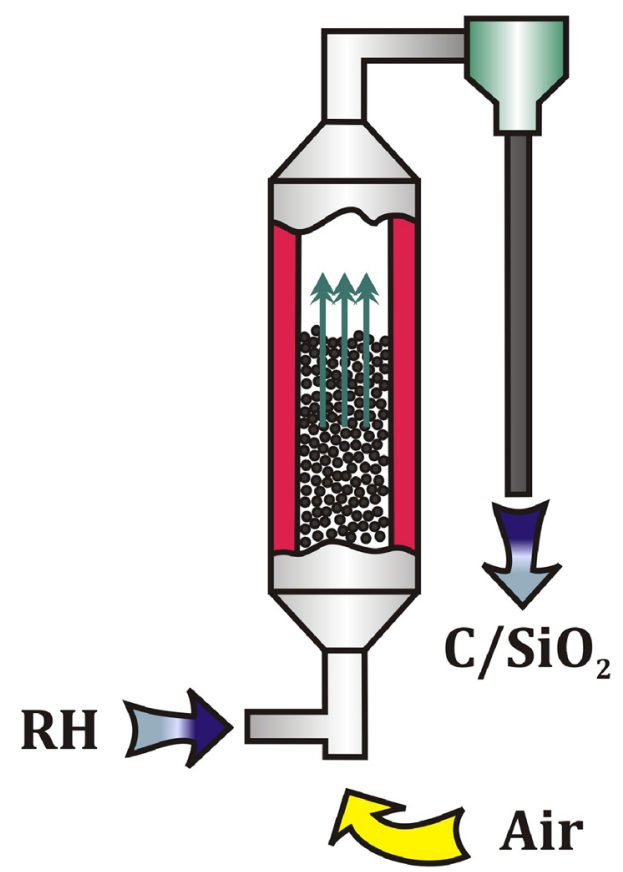

Fig. 2 Scheme of fluidized catalyst bed reactor with deep oxidation catalyst for $\mathrm{RH}$ carbonization at $465-600{ }^{\circ} \mathrm{C}$ conditions of the carbons synthesis and designation of the samples are summarized.

More detailed information on the preparation of $\mathrm{C} / \mathrm{SiO}_{2}$ composites from RH and their alkali and carbonate activation is represented in [21-23].

\section{Characterization of carbons}

Textural characteristics of the prepared samples were obtained from the isotherms of nitrogen adsorption measured at $77 \mathrm{~K}$ by means of an automatic volumetric device ASAP 2400 (Micrometritics, USA). Isotherms of adsorption of carbon dioxide at $273.15 \mathrm{~K}$ were measured by means of Autosorb-6B-Kr adsorption analyzer (Quantachrome Instruments, USA). Before measurement, all samples were degassed by evacuation at $1.5 \mathrm{~Pa}$ and heating at $350{ }^{\circ} \mathrm{C}$ during $10 \mathrm{~h}$. The samples were pre-treated at $423 \mathrm{~K}$ under residual pressure of ca. 10 mTorr. The BET surface area, $A_{\mathrm{BET}}$, was calculated from the adsorption isotherms under relative pressures $P / P_{0}\left(P_{0}\right.$ is the saturation pressure) of $0.05-0.2$, correspondingly. Total mesopore and micropore volume were also calculated from pore size distribution obtained using non-local density functional theory (NLDFT). Mesopore size distribution was calculated from isotherms of nitrogen adsorption using NLDFT $\mathrm{N}_{2}$-carbon kernel based on slit-like pore model for pore size less than $2 \mathrm{~nm}$ and on cylinder-like pore model for larger pore. Micropore size distribution was calculated using NLDFT $\mathrm{CO}_{2}$-carbon kernel based on slit-like pore model at $273 \mathrm{~K}$. All calculations were carried out using the software supplied with the instrument.

\section{Preparation of the electrodes and electrochemical measurements}

For the working electrode preparation, mixture of the porous carbon sample, carbon black and polytetrafluoroethylene (PTFE) in ratio 80:10:10 in water with a few drops of isopropanol was treated in ultrasonic bath during 20 min. PTFE was used as binder and carbon black as conductive additive. Then, the obtained mixture was dried in an oven at $130{ }^{\circ} \mathrm{C}$ during $5 \mathrm{~h}$. Working electrodes in the form of $1 \mathrm{~cm}$ diameter pellets (ca. $15 \mathrm{mg}$ ) were obtained by pressing the mixture. The experiments were performed in a three-electrode cell in $1 \mathrm{M} \mathrm{H}_{2} \mathrm{SO}_{4}$ as an electrolyte.

Table 1 Texture characteristics of $\mathrm{RH}$ carbonized in FCB reactor at $465-600{ }^{\circ} \mathrm{C}$

\begin{tabular}{|c|c|c|c|c|}
\hline$T_{\mathrm{FCB}}\left({ }^{\circ} \mathrm{C}\right)$ & $A_{\mathrm{BET}}\left(\mathrm{m}^{2} / \mathrm{g}\right)$ & $V_{\Sigma,}\left(\mathrm{cm}^{3} / \mathrm{g}\right)$ & $V_{\mu},\left(\mathrm{cm}^{3} / \mathrm{g}\right)$ & Ash (wt\%) \\
\hline 465 & 180 & 0.18 & 0.03 & 59.6 \\
\hline 550 & 210 & 0.19 & 0.03 & 73.9 \\
\hline 600 & 220 & 0.22 & 0.03 & 81.5 \\
\hline
\end{tabular}


Table 2 Conditions of carbon samples preparation by carbonate and alkali activation from carbonized RH

\begin{tabular}{llllll}
\hline Sample & $T_{\text {car }}\left({ }^{\circ} \mathrm{C}\right)$ & $T_{\text {act }}\left({ }^{\circ} \mathrm{C}\right)$ & $\tau_{\text {act }}(\mathrm{h})$ & Act. agent & Molar ratio of carbonates to $\mathrm{SiO}_{2}$ \\
\hline \multicolumn{2}{l}{ Carbonate activation } & & & & \\
C540 & 465 & 1000 & 3 & $\mathrm{~K}_{2} \mathrm{CO}_{3} / \mathrm{Na}_{2} \mathrm{CO}_{3}$ & $3: 1$ \\
C890 & 600 & 900 & 2 & $\mathrm{~K}_{2} \mathrm{CO}_{3}$ & $1: 1$ \\
C990 & 465 & 950 & 1 & $\mathrm{~K}_{2} \mathrm{CO}_{3} / \mathrm{Na}_{2} \mathrm{CO}_{3}$ & $1: 1$ \\
C1100 & 465 & 1000 & 1 & $\mathrm{~K}_{2} \mathrm{CO}_{3} / \mathrm{Na}_{2} \mathrm{CO}_{3}$ & $3: 2$ \\
C1400 & 550 & 900 & 0.5 & $\mathrm{~K}_{2} \mathrm{CO}_{3} / \mathrm{Na}_{2} \mathrm{CO}_{3}$ & $2: 1$ \\
Alkali activation & & & & & - \\
C2230 & 465 & 800 & 1 & $\mathrm{NaOH}$ & - \\
C2700 & 465 & 750 & - & $\mathrm{KOH}$ & - \\
C3060 & 465 & 750 & - & $\mathrm{KOH}$ & \\
\hline
\end{tabular}

* Samples designation were made accordingly with their BET specific surface area

$T_{\text {car }}$-temperature of $\mathrm{RH}$ carbonization

$T_{\text {act }}$-temperature of the activation

$\tau_{\text {act }}$-time of the activation

Counter electrode was platinized platinum and carbon electrode for the high-surface area samples; $\mathrm{Hg} / \mathrm{HgSO}$ electrode was used as reference electrode. All potential values in the article are reported versus reversible hydrogen electrode (RHE). Electrochemical measurements were performed using a potentiostat/galvanostat Autolab PGSTAT 30. Electrochemical characteristics of the carbon materials were examined by cyclic voltammetry with $1 \mathrm{mV} / \mathrm{s}$ scan rate and chronopotentiometry at current densities from $0.2 \mathrm{~A} / \mathrm{g}$ to $2 \mathrm{~A} / \mathrm{g}$.

\section{Results and discussion}

\section{Textural characteristics of the carbons}

Carbon materials were synthesized by the activation of carbonized rice husk at the different activation condition. Their textural characteristics are shown in Table 3.

Combination of the preparation conditions allowed to obtain series of the carbon with textural characteristics varied in the wide range. Higher activation temperature (900-1000 ${ }^{\circ} \mathrm{C}$ ) and carbonates as activated agents lead to materials with $A_{\mathrm{BET}}=540-1400 \mathrm{~m}^{2} / \mathrm{g}$. Decrease in the temperature to $750-800{ }^{\circ} \mathrm{C}$ and utilization of the alkalis allow to obtain samples with more developed porosity and significantly higher BET surface area (C2230-C3060) close to the highest possible for the porous carbons [22].

Under the carbonate activation process, the porosity of carbonized RH is developed mainly due to "leaching out" of the template silica phase in the form of water-soluble silicates and interaction of carbon phase with $\mathrm{CO}_{2}$ which is formed as a product of $\mathrm{SiO}_{2}$ and carbonates interaction. Besides that, carbon phase is able to interact with carbonates themselves with microporosity developing, especially in the case of molar ratios of carbonates to $\mathrm{SiO}_{2}$ more than 1:1 [23]. In whole, carbonate activation leads to obtaining carbons with $A_{\mathrm{BET}}=800-1400 \mathrm{~m}^{2} \mathrm{~g}^{-1}$, possessing porosity shifted to mesopore area [23]. In the case of alkalis, porosity development in the carbons is due to interaction of alkalis both with $\mathrm{SiO}_{2}$ and carbon phases, but the carbon phase seems to undergo significant reconstruction because of interaction of alkalis with carbon via oxygen-containing surface functional groups. Previous studies have shown no or enough low porosity development under activation of graphite or carbon nanofibers by $\mathrm{KOH}$, in comparison with activation of the carbonized $\mathrm{RH}$ [22].

Isotherms of nitrogen adsorption on carbonized rice husk with $A_{\mathrm{BET}}=540-1400 \mathrm{~m}^{2} \mathrm{~g}^{-1}$ (Fig. 3a) show H4type hysteresis which is characteristic for microporous materials with wide mesopore size distribution without well-defined or tailored pore size. Pore size distribution calculated using NLDFT (Fig. 4, Series 1) applied to nitrogen and carbon dioxide isotherms on all samples is rather similar to each other with micropore fraction in total pore volume $20-30 \%$. The pore size distribution demonstrates no plateau up to pore size of $40 \mathrm{~nm}$. The main texture characteristic, which really changes in the series, is the total pore volume or the porosity. Total micropore volume calculated from $\mathrm{CO}_{2}$ adsorption is quite close to such volume calculated from $\mathrm{N}_{2}$ adsorption. The only appreciable exception in the series is the sample C890, which shows more micropore volume calculated from $\mathrm{CO}_{2}$ 
Table 3 Textural characteristics and ash content of the porous carbon samples, produced from the carbonized rice husk

\begin{tabular}{|c|c|c|c|c|c|}
\hline Sample & $A_{\mathrm{BET}}\left(\mathrm{m}^{2} / \mathrm{g}\right)$ & $\begin{array}{l}V_{\text {pore }}\left(\mathrm{cm}^{3} / \mathrm{g}\right) \\
1.5-40 \mathrm{~nm}\end{array}$ & $\begin{array}{l}V_{\mu}^{\mathrm{CO}_{2}}\left(\mathrm{~cm}^{3} / \mathrm{g}\right) \\
0-1.5 \mathrm{~nm}\end{array}$ & $V_{\mu}^{\mathrm{CO}_{2}} /\left(V_{\text {pore }}+V_{\mu}^{\mathrm{CO}_{2}}\right)(\%)$ & Ash (\%) \\
\hline C540 & 540 & 0.47 & 0.12 & 20 & 15.7 \\
\hline C890 & 890 & 0.74 & 0.26 & 26 & 30.2 \\
\hline C990 & 990 & 0.66 & 0.29 & 31 & 8.9 \\
\hline $\mathrm{C} 1100$ & 1100 & 0.75 & 0.30 & 28 & 9.4 \\
\hline $\mathrm{C} 1400$ & 1400 & 0.74 & 0.32 & 30 & 14.4 \\
\hline $\mathrm{C} 2230$ & 2230 & 0.81 & 0.44 & 35 & 8.2 \\
\hline $\mathrm{C} 2700$ & 2700 & 0.99 & 0.40 & 29 & 6.2 \\
\hline C3060 & 3060 & 1.99 & 0.47 & 19 & 2.8 \\
\hline
\end{tabular}

Fig. $3 \mathrm{~N}_{2}$ adsorption and desorption isotherms at $77 \mathrm{~K}$ for a C540-C1400 and b C2230 C3060 samples
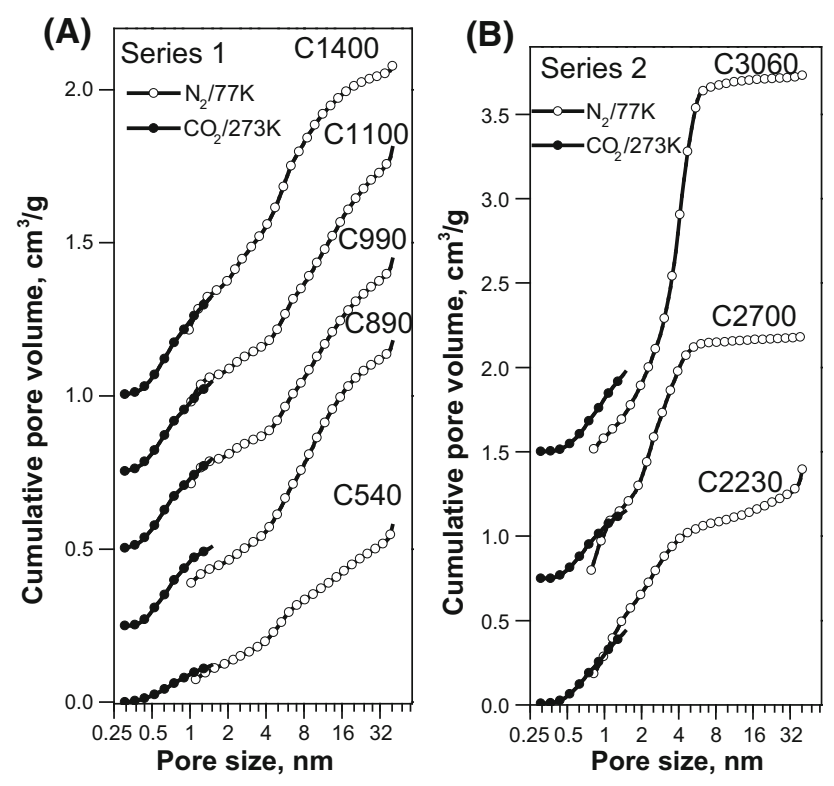

Fig. 4 Micropore and mesopore size distribution calculated using

NLDFT from isotherms of adsorption $\mathrm{CO}_{2} / 273 \mathrm{~K}$ and $\mathrm{N}_{2} / 77 \mathrm{~K}$
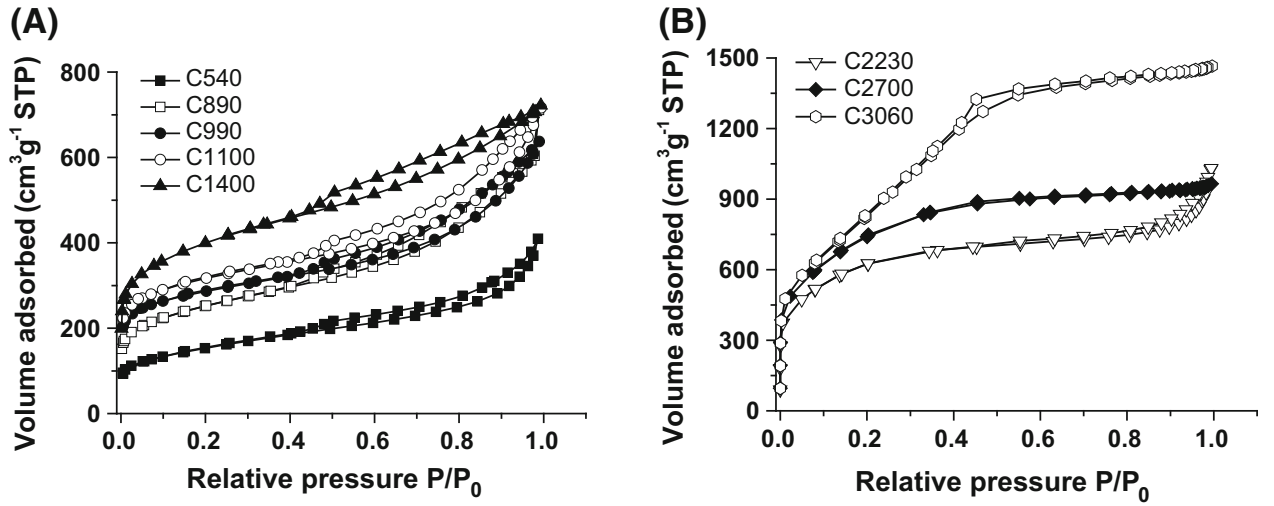

adsorption. This fact could be explained by well-known phenomenon activated adsorption in this material at cryogenic temperature [25].

Isotherms of nitrogen adsorption on samples obtained by alkalis activation (Fig. 3b) show a plateau without hysteresis loop at the relative pressure more than 0.4. Such behavior could indicate the existence of narrow size distribution of either micro- or mesopore. This fact is well illustrated by pore size distribution (Fig. 4, Series 2). As in the case of samples with lower $\mathrm{A}_{\mathrm{BET}}$, the micropore size distribution taken from $\mathrm{CO}_{2}$ adsorption agrees with pore size distribution calculated from $\mathrm{N}_{2}$ adsorption. The exception is the sample $\mathrm{C} 3060$ that shows much more micropore volume calculated from $\mathrm{CO}_{2}$ adsorption, which could be explained by activated nitrogen adsorption on this sample at cryogenic temperature [25]. Pore size distribution on the series demonstrates a visible plateau for pore size more than $4 \mathrm{~nm}$. The total micropore volume in the series is near to constant, whereas the mesopore volume increases in the row C2232 < C2700 < C3060. 


\section{Electrochemical properties of the carbon materials}

Cyclic voltammograms of the electrodes recorded at $1 \mathrm{mV} /$ $\mathrm{s}$ are presented in Fig. 5a. The magnitude of the observed current is increased with increasing the carbon surface area, which indicates the increase of the capacitance. CVs are characterized by the symmetric, close to rectangular shape indicating good ion diffusion into the bulk of the electrodes. However, some deviation from the rectangular shape is observed for the sample with the highest surface area, C3060. It is most likely connected with increased self-resistance of the material typical for the high-surface area carbons. Pair of the weak reversible peak (around $0.6 \mathrm{~V}$ ) on the $\mathrm{CV}$ curves of the all samples is associated with quinone/hydroquinone couples (QHC) on the surface of the carbon [26]. Intensity of the current related to those peaks is minor which supposes negligible contribution to the overall capacitance.

Capacitance of the samples has been determined by the chronopotentiometry method (CPM) in the potential range from 0.05 to $0.95 \mathrm{~V}$ vs RHE. Utilization of CPM allows to determine dependence of the capacitance from the charge/ discharge rate by varying current densities. Charge and discharge current density was varied from $0.2 \mathrm{~A} / \mathrm{g}$ to $2 \mathrm{~A} /$ g. The charge/discharge curves at $0.2 \mathrm{~A} / \mathrm{g}$ for the C890, C2230 and C3060 are presented in Fig. 5b. The curves for the rest of the samples are not shown due to the similarity in the behavior and differ only time of the charge/discharge processes.

All charge and discharge curves are started with initial IR drop usually associated partially with equivalent series resistance (ESR) and individual pore resistance specific for the porous materials $[27,28]$. Drop value is on the same level for the all samples. The shape of the curves is symmetrical and close to linear with an insignificant deviation from linearity due to the presence of some amount of QHC, which is more pronounced for the samples C2700 (not shown) and C3060. Such behavior characterizes samples as an electric double layer capacitor with a negligible contribution of the pseudocapacitance. C3060 possesses the longest times of the charge and discharge indicating high capacitive performance. Coulombic efficiency lies in range 98-99\%.

Based on the data obtained by the chronopotentiometry method, the capacitance has been calculated using the following equation from the discharge curve:

$C=\frac{i \times \mathrm{d} t}{\mathrm{~d} E \times x}$

where $C(F)$ - capacitance, $i(A)$ - discharge current, $t(s)$ discharge time, $E(V)$-potential window, $x$-either mass $(\mathrm{g})$ or specific surface area $\left(\mathrm{m}^{2}\right)$ of the electrode.

Values of gravimetric $\left(C_{\mathrm{g}}\right)$ and surface $\left(C_{\mathrm{s}}\right)$ capacitance obtained at the chosen discharge current density and performance rating $C_{2} / C_{0.2}$ are listed in Table 4 . The dependence of the relative capacitance on the current density is shown in Fig. 6a.

As expected, sample with the highest surface area, C3060, possesses the highest gravimetric capacitance at all examined discharge current densities (0.2-2 A/g). Farther, with decreasing the specific surface area, the capacitance gradually decreases and reaches minimum for the sample with the smallest surface area, C540.

At the relatively slow charge/discharge rate, i.e., $0.2 \mathrm{~A} /$ $\mathrm{g}$, each sample demonstrates the highest intrinsic to its value of capacitance. Progressive increase of the current density to the higher charge/discharge rate $(2 \mathrm{~A} / \mathrm{g})$ leads to the decrease in the gravimetric capacitance. However, degree of decay is around $15 \%$ for the all samples (Fig. 6a), which means a good rate performance. The good rate performance is provided by the relatively low micropore fraction (20-30\% independently of the surface area

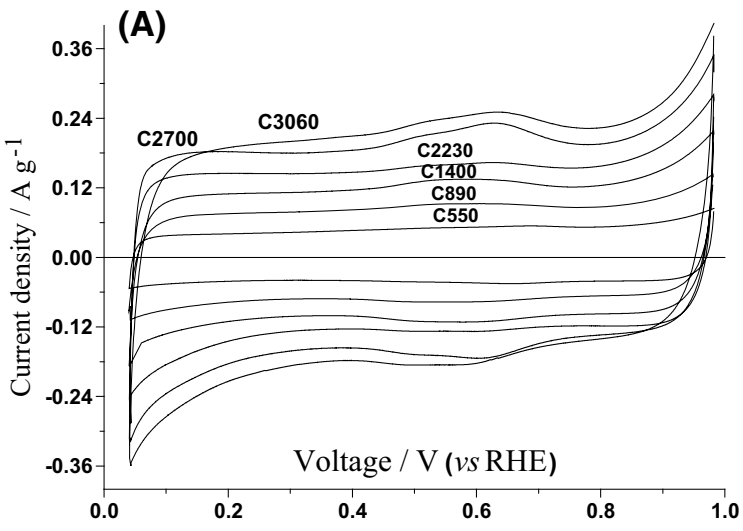

(B)

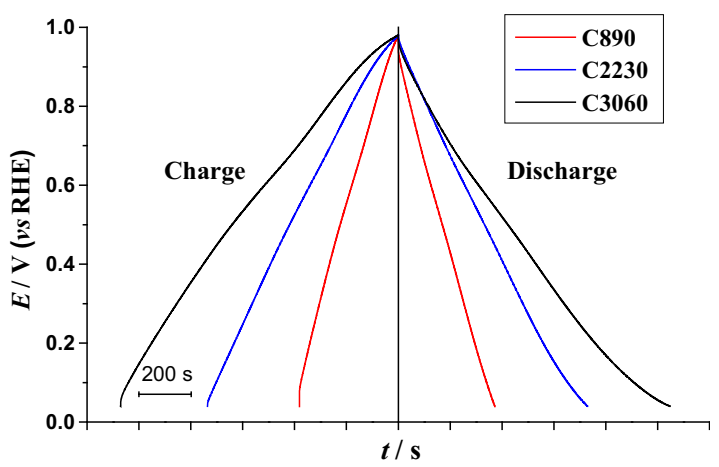

Fig. 5 a Cyclic voltammograms of the studied samples recorded at $1 \mathrm{mV} / \mathrm{s}$; b Charge/discharge curves at 0.2 A/g. Supporting electrolyte: $1 \mathrm{M} \mathrm{H}_{2} \mathrm{SO}_{4}$ 
Table 4 Gravimetric and surface capacitance at different values of discharge current densities

\begin{tabular}{|c|c|c|c|c|c|c|c|}
\hline \multirow[t]{2}{*}{ Sample } & \multicolumn{4}{|l|}{$C_{\mathrm{g}}(\mathrm{F} / \mathrm{g})$} & \multicolumn{3}{|c|}{$C_{\mathrm{s}}\left(\mathrm{F} / \mathrm{m}^{2}\right)$} \\
\hline & $0.2 \mathrm{~A} / \mathrm{g}$ & $1 \mathrm{~A} / \mathrm{g}$ & $2 \mathrm{~A} / \mathrm{g}$ & $C_{2} / C_{0.2}$ & $0.2 \mathrm{~A} / \mathrm{g}$ & $1 \mathrm{~A} / \mathrm{g}$ & $2 \mathrm{~A} / \mathrm{g}$ \\
\hline C3060 & 230 & 196 & 195 & 0.85 & 0.075 & 0.064 & 0.064 \\
\hline $\mathrm{C} 2700$ & 200 & 178 & 180 & 0.90 & 0.074 & 0.066 & 0.067 \\
\hline $\mathrm{C} 2230$ & 166 & 147 & 142 & 0.87 & 0.074 & 0.063 & 0.063 \\
\hline C1400 & 125 & 111 & 110 & 0.89 & 0.088 & 0.079 & 0.079 \\
\hline $\mathrm{C} 1100$ & 90 & 83 & 75 & 0.84 & 0.082 & 0.076 & 0.070 \\
\hline C990 & 86 & 77 & 70 & 0.82 & 0.088 & 0.077 & 0.072 \\
\hline C890 & 83 & 77 & 74 & 0.89 & 0.094 & 0.086 & 0.083 \\
\hline C540 & 47 & 43 & 40 & 0.86 & 0.084 & 0.078 & 0.072 \\
\hline
\end{tabular}
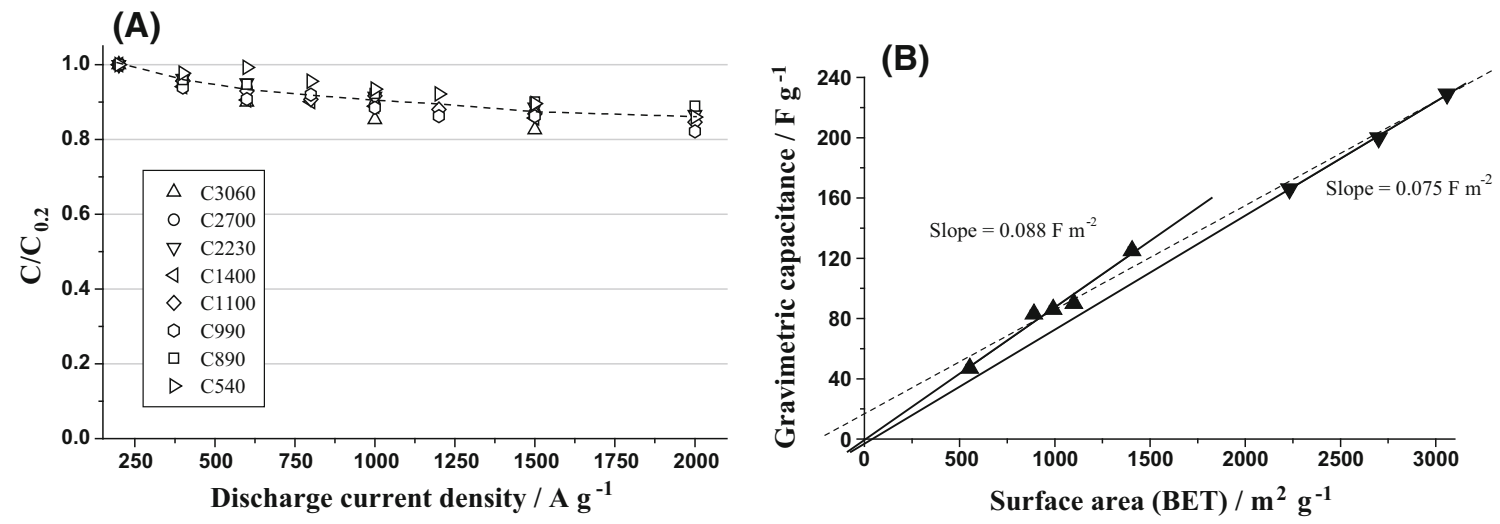

Fig. 6 a Relative capacitance $\left(C / C_{0.2}\right)$ versus discharge current density. b Gravimetric capacitance versus BET surface area. The data were obtained by galvanostatic charge/discharge at $0.2 \mathrm{~A} / \mathrm{g}$ with $0.9 \mathrm{~V}$ voltage window in $1 \mathrm{M} \mathrm{H}_{2} \mathrm{SO}_{4}$

of the carbons, see Table 1) giving almost complete availability of the carbon surface for the electrolyte ions.

The dependence of the gravimetric capacitance from the surface area of the studied carbons is depicted in Fig. 6b. Capacitance change is almost linear with the specific surface area. However, correlation line does not intercept zero point, which does not have realistic explanation. Slope of the correlation line is $0.068 \mathrm{~F} / \mathrm{g}$ which is less than the calculated $\mathrm{C}_{\mathrm{s}}$ of any presented samples at that discharge current density (see Table 4). However, taking into account textural features of the carbons, samples can be divided into two groups in compliance with their pore structure. Such separation gives more reasonable results. Inside each group, correlation line intercepts zero point within experimental error and slope corresponds to the average values of the surface capacitance (see Table 4; Fig. 6b). Such observation is correct through the all examined current density range. Samples in series C540-C1400 possess higher average surface capacitance compared to the samples with higher surface area (C2230-C3060), $0.088 \mathrm{~F} / \mathrm{m}^{2}$ and $0.075 \mathrm{~F} / \mathrm{m}^{2}$ at $0.2 \mathrm{~A} / \mathrm{g}$, respectively. Higher surface capacitance of the samples in the sequence C540-C1400 can be explained by wider pore size distribution resulting in more surface accessibility. Changes in the pore structure and porosity increase for samples C2230, C2700 and C3060 lead to restriction of surface availability for electrolyte ions and consequently to decrease in value of the surface capacitance.

The dependence of the capacitance from the surface area is varied by way of preparation, origin of precursors and electrolyte species, textural characteristics and surface functionality of carbon materials. In some cases, dependence either does not observe at all or observe in a limited range of the surface area values. Thus, studies of the activated carbons [29-32] and activated carbon nanofibers [33] showed that after some critical value (in most of cases around $1500 \mathrm{~m}^{2} / \mathrm{g}$ ) capacitance becomes independent of the surface area. Tendency to saturation supports by the idea that only limited available for the electrolyte surface takes part in the formation of the electric double layer. On the contrary, no correlation of capacitance and surface area was found on plasma-treated carbon nanofibers [34] and 
various activated carbons $[35,36]$. Absence of the dependency is explained by the different factors governing double layer formation, main of which is presence of the oxygen-content groups and specific porous structure.

In the presented study, increase in the gravimetric capacitance with surface area is absolutely clear. Particularly, it should be emphasized that the linearity is kept up to high values of the surface area $\left(\sim 3000 \mathrm{~m}^{2} / \mathrm{g}\right)$. Linear dependence points out that the surface area is a determinative factor providing good capacitive performance. Utilization of the rice husk as the template-containing precursor allowed to prepare carbon materials with textural properties suitable for application as electrode materials in the supercapacitors.

\section{Conclusions}

In summary, activated carbons have been successfully produced from the rice husk carbonized in the fluidized catalyst bed reactor. Variation of the preparation conditions allowed to obtain carbon materials with surface area varied in wide range, from 540 to $3060 \mathrm{~m}^{2} / \mathrm{g}$ and, which should be emphasized especially, with close values of the micropore fraction $(20-30 \%)$. Linear dependence of the gravimetric capacitance from BET surface area was found, suggesting the surface area as crucial factors for the formation of the electric double layer and obtaining appropriate capacitive performance. Surface capacitance poorly depends on the surface area which is a characterized material surface as available for the electrolyte ions with insignificant diffusion limitation. Thus, utilization of the RH as templatecontaining precursor allows to prepare materials with textural characteristics attractive for the application in the supercapacitors.

Acknowledgments This work was supported by Russian Academy of Science, Project No. V.46.4.4.

Open Access This article is distributed under the terms of the Creative Commons Attribution 4.0 International License (http:// creativecommons.org/licenses/by/4.0/), which permits unrestricted use, distribution, and reproduction in any medium, provided you give appropriate credit to the original author(s) and the source, provide a link to the Creative Commons license, and indicate if changes were made.

\section{References}

1. Burke, A.: R\&D considerations for the performance and application of electrochemical capacitors. Electrochim. Acta 53, 1083-1091 (2007)

2. Conte, M.: Supercapacitors technical requirements for new applications. Fuel cells 10, 806-818 (2010)
3. Zhang, Y., Feng, H., Wu, X., Wang, L., Zhang, A., Xia, T., Dong, H., Li, X., Zhang, L.: Progress of electrochemical capacitor electrode materials: a review. Int. J. Hydrog. Energy 34, 4889-4899 (2009)

4. Pandolfo, A.G., Hollenkamp, A.F.: Carbon properties and their role in supercapacitors. J. Power Sources 157, 11-27 (2006)

5. He, X., Ling, P., Yu, M., Wang, X., Zhang, X., Zheng, M.: Rice husk-derived porous carbons with high capacitance by $\mathrm{ZnCl}_{2}$ activation for supercapacitors. Electrochim. Acta 105, 635-641 (2013)

6. Demarconnay, L., Raymundo-Piñero, E., Béguin, F.: A symmetric carbon/carbon supercapacitor operating at $1.6 \mathrm{~V}$ by using a neutral aqueous solution. Electrochem. Commun. 12, 1275-1278 (2010)

7. Yamada, Y., Sasaki, T., Tatsuda, N., Weingarth, D., Yano, K., Kötz, R.: A novel model electrode for investigating ion transport inside pores in an electrical double-layer capacitor: monodispered microporous starburst carbon spheres. Electrochim. Acta 81, 138-148 (2012)

8. Ruiz, V., Blanco, C., Raymundo-Pinero, E., Khomenko, V., Beguin, F., Santamaria, R.: Effects of thermal treatment of activated carbon on the electrochemical behaviour in supercapacitors. Electrochim. Acta 52, 4969-4973 (2007)

9. Ito, E., Mozia, S., Okuda, M., Nakano, T., Toyoda, M., Inagaki, M.: Nanoporous carbons from cypress II. Application to electric double layer capacitors. New Carbon Mater. 22, 321-326 (2007)

10. He, X., Ling, P., Qiu, J., Yu, M., Zhang, X., Yu, Ch., Zheng, M.: Efficient preparation of biomass-based mesoporous carbons for supercapacitors with both high energy density and high power density. J. Power Sources 240, 109-113 (2013)

11. Li, H., Xi, H., Zhu, S., Wen, Zh, Wang, R.: Preparation, structural characterization, and electrochemical properties of chemically modified mesoporous carbon. Microporous Mesoporous Mater. 96, 357-362 (2006)

12. Prabaharan, S.R.S., Vimala, R., Zainal, Z.: Nanostructured mesoporous carbon as electrodes for supercapacitors. J. Power Sources 161, 730-736 (2006)

13. Peng, C., Yan, X., Wang, R., Lang, J., Ou, Y., Xue, Q.: Promising activated carbons derived from waste tea-leaves and their application in high performance supercapacitors electrodes. Electrochim. Acta 87, 401-408 (2013)

14. Lee, S.G., Park, K.H., Shim, W.G., Balathanigaimani, M.S., Moon, H.: Performance of electrochemical double layer capacitors using highly porous activated carbons prepared from beer lees. J. Ind Eng Chem. 17, 450-454 (2011)

15. Ding, L., Zou, B., Li, Y., Liu, H., Wang, Z., Zhao, C., Su, Y., Guo, Y.: The production of hydrochar-based hierarchical porous carbons for use as electrochemical supercapacitor electrode materials. Colloids Surf. A 423, 104-111 (2013)

16. Mitani, S., Lee, S.I., Yoon, S.H., Korai, Y., Mochida, I.: Activation of raw pitch coke with alkali hydroxide to prepare high performance carbon for electric double layer capacitor. J. Power Sources 133, 298-301 (2004)

17. Benaddi, H., Bandosz, T.J., Jagiello, J., Schwarz, J.A., Rouzaud, J.N., Legras, D., Beguin, F.: Surface functionality and porosity of activated carbons obtained from chemical activation of wood. Carbon 38, 669-674 (2000)

18. Hu, Z.H., Vansant, E.F.: Synthesis and characterization of a controlled-micropore-size carbonaceous adsorbent produced from walnut shell. Microporous Mater. 3, 603-612 (1995)

19. Liu, M., Kong, L., Zhang, P., Luo, Y., Kang, L.: Porous wood carbon monolith for high-performance supercapacitors. Electrochim. Acta 60, 443-448 (2012)

20. Kumagaia, S., Sato, M., Tashima, D.: Electrical double-layer capacitance of micro- and mesoporous activated carbon prepared 
from rice husk and beet sugar. Electrochim. Acta 114, 617-626 (2013)

21. Eletskii, P.M., Yakovlev, V.A., Kaichev, V.V., Yazykov, N.A., Parmon, V.N.: Texture and surface properties of carbon-silica nanocomposite materials prepared by the carbonization of highash vegetable raw materials in a fluidized catalyst bed. Kinet. Catal. 49, 305-312 (2008)

22. Eletskii, P.M., Yakovlev, V.A., Fenelonov, V.B., Parmon, V.N.: Texture and adsorptive properties of microporous amorphous carbon materials prepared by the chemical activation of carbonized high-ash biomass. Kinet. Catal. 49, 708-719 (2008)

23. Yeletsky, P.M., Yakovlev, V.A., Mel'gunov, M.S., Parmon, V.N.: Synthesis of mesoporous carbons by leaching out natural silica templates of rice husk. Microporous Mesoporous Mater. 121, 34-40 (2009)

24. Larichev, YuV, Eletskii, P.M., Tuzikov, F.V., Yakovlev, V.A.: Porous carbon-silica composites and carbon materials from rice husk: production technology, texture, and dispersity. Catal. Ind. 5, 350-357 (2013)

25. Gregg, S.J., Sing, K.S.W.: Adsorption, Surface Area and Porosity, 2nd edn. Academic Press, New York (1982)

26. Kinoshita, K.: Carbon: Electrochemical and Physicochemical Properties, pp. 306-316. John and Wiley Sons, New York (1988)

27. Pell, W.G., Conway, B.E., Marincic, N.: Analysis of non-uniform charge:discharge and rate effects in porous carbon capacitors containing sub-optimal electrolyte concentrations. J. Electroanal. Chem. 491, 9-21 (2000)

28. Pell, W.G., Conway, B.E., Adams, W.A., Oliveira, J.: Electrochemical efficiency in multiple discharger/recharge cycling of supercapacitors in hybrid EV applications. J. Power Sources 80, 134-141 (1999)
29. Wang, L.-H., Toyoda, M., Inagaki, M.: Dependence of electric double layer capacitance of activated carbons on the types of pores and their surface areas. New Carbon Mater. 23(2), 111-115 (2008)

30. Inagaki, M., Konno, H., Tanaike, O.: Carbon materials for electrochemical capacitors. J. Power Sources 195, 7880-7903 (2010)

31. Gryglewicz, G., Machnikowski, J., Lorenc-Grabowska, E., Lota, G., Frackowiak, E.: Effect of pore size distribution of coal-based activated carbons on double layer capacitance. Electrochim. Acta 50, 1197-1206 (2005)

32. Barbieri, O., Hahn, M., Herzog, A., Kötz, R.: Capacitance limits of high surface area activated carbons for double layer capacitors. Carbon 43, 1303-1310 (2005)

33. Toyoda, M., Tani, Y., Soneda, Y.: Exfoliated carbon fibers as an electrode for electric double layer capacitors in a $1 \mathrm{~mol} / \mathrm{dm}^{3}$ $\mathrm{H}_{2} \mathrm{SO}_{4}$ electrolyte. Carbon 42, 2833-2837 (2004)

34. Okajima, K., Ohta, K., Sudoh, M.: Capacitance behavior of activated carbon fibers with oxygen-plasma treatment. Electrochim. Acta 50, 2227-2231 (2005)

35. Gamby, J., Taberna, P.L., Simon, P., Fauvarque, J.F., Chesneau, M.: Studies and characterisations of various activated carbons used for carbon/carbon supercapacitors. J. Power Sources 101, 109-116 (2001)

36. Bleda-Martínez, M.J., Maciá-Agulló, J.A., Lozano-Castelló, D., Morallón, E., Cazorla-Amorós, D., Linares-Solano, A.: Role of surface chemistry on electric double layer capacitance of carbon materials. Carbon 43, 2677-2684 (2005) 